\title{
La víctima simulada. Identidades forzadas en la violencia de género
}

\author{
David CASADO-NEIRA \\ Universidade de Vigo (España) \\ dcneira@uvigo.es
}

\author{
María MARTíNEZ \\ University of California Santa Barbara (EE.UU.) \\ y Universidad del País Vasco / Euskal Herriko Unibertsitatea (España) \\ maria.martinezg@ehu.eus
}

Recibido: 30-07-2015

Aceptado: 12-04-2016

\begin{abstract}
Resumen
En las sociedades contemporáneas la víctima es una figura cada vez más extendida. En el caso español, la víctima de la violencia de género ha venido a ocupar una posición central en esta generalización, en un proceso acentuado por la Ley Integral contra la violencia de género que ha supuesto un alto grado de institucionalización en su tratamiento. Partiendo principalmente del análisis de entrevistas a mujeres objeto de malos tratos se plantea que la especificidad de la víctima de violencia de género no radica ni en el origen o la causa ni en su grado de sufrimiento, sino en la respuesta institucional a esa situación, en la forma en la que se activan los dispositivos institucionales que configuran su identidad. Se identifican tres hitos en el itinerario que sigue una víctima institucionalizada de violencia de género: la revelación, la agencia y la vida simulada. Los diferentes dispositivos que se ponen en marcha dan lugar a un proceso de tutorización basado en un mandato moral para que deje de ser víctima. En una tensión paradójica ha de victimizarse para desvictimizarse, reconocerse como tal pero no consolidarse en esa identidad, ha de empoderarse a través de una toma de conciencia de su situación, y ajustarse a un patrón de víctima creíble o buena víctima, aquella que se deja rescatar por los dispositivos, que se deja salvar de sí misma.
\end{abstract}

Palabras clave: Víctima; violencia de género; identidad; agencia; simulación.

\section{Compeled Identities in Gender Violence: the Simulated Victim}

\begin{abstract}
In the contemporary world 'being a victim' has become a more widespread condition. In the last years in Spain, the victim of gender violence has turned into a central position among all other victims. The woman who suffers gender violence is assisted by a specific law, this has led to a highly institutionalized treatment of the victim, which includes specialized police units, courts, forensic scientists, social workers and psychologists, among other. After interviewing, mainly, women who have, first, suffered abuses and, after, received institutional support, it was found that, what defines the gender violence victims of gender
\end{abstract}

${ }^{1}$ Beneficiaria del programa de perfeccionamiento de personal investigador doctor del Gobierno Vasco (2016-2018). 
as a social figure, is not the set of suffered aggressions, neither their degree of subjective suffering, but the institutional response to their situation: the way the activated institutional practices and assistance instruments shape the victims' identities. Three milestones can be identified in the institutional itinerary of victims of gender violence: the revelation, the agency and the simulated life. The victim is supervised by different institutional mechanisms and protocols under the principe of a moral mandate: she has to stop being a victim. In a paradoxical tension she is pushed to identify herself as a victim to leave this position inmediately, an identity lived as a moment of passage, she must empower herself by taking awareness of her situation. In this institutional context the gender violence victim has to perform, according to the no written patterns, a credible -or good- victim: one that accepts being rescued from herself.

Key words: Victim; gender violence; identity; agency; simulation.

\section{Referencia normalizada}

Casado-Neira, D. y M. Martínez (2016): "La víctima simulada. Identidades forzadas en la violencia de género", Política y Sociedad, 53 (3), pp. 879-896.

Sumario: Agradecimientos. Introducción. 1 Apunte metodológico. 2. Los hitos de la víctima simulada. 3. Reflexiones finales. 4. Bibliografía.

\section{Agradecimientos}

Este texto es producto del proyecto de investigación Mundo(s) de víctimas. Dispositivos y procesos de construcción de la víctima en la España contemporánea. Estudio de cuatro casos paradigmáticos (CSO 2011-22451), proyecto con sede en la Universidad del País Vasco/Euskal Herriko Unibertsitatea y financiado por el Ministerio de Ciencia e Innovación español dentro del Plan Nacional de I+D+i. Se ha desarrollado entre 2012 y 2015 por un amplio equipo multidisciplinar e internacional.

\section{Introducción}

Desde finales de la década de los 90 la violencia de género ha venido ganando una presencia cada vez mayor en la preocupación de las políticas oficiales y de las campañas institucionales de concienciación social (Bengoechea, 2007) que culminará con la aprobación de la Ley orgánica 1/2004, de 28 de diciembre, de medidas de protección integral contra la violencia de género - a partir de ahora Ley Integral-(España, 2004). De hecho, también, hemos asistido paralelamente a cómo la violencia doméstica ha pasado a ser considerada un concepto limitado e inexacto que contribuye a ocultar su dimensión real (Lorente, 2001: 38; Debén, 2006) debido, precisamente, al carácter estructural de esta forma de malos tratos y a su trascendencia en el proyecto de configuración de una sociedad en un proceso de modernización que demanda una mayor presencia de las mujeres en los ámbitos económico, político y cultural. La visibilización de la mujer objeto de malos tratos supuso la aparición en el escenario público de un nuevo tipo de víctima que, saliendo de la esfera estrictamente privada y doméstica, se convierte en una figura que representa la forma más nuclear de las desigualdades de género.

En un sentido amplio se puede afirmar que la víctima (todas) ha ido emergiendo como una figura central en la configuración de la ciudadanía actual. Judith Butler (2006: 45-78) la entiende como una forma de constitución de una nueva ciudadanía a través 
del reconocimiento de la vulnerabilidad (social y física), principio moral y político de un nuevo humanismo. Ello permite intuir una "era de la víctima" (Gatti, 2014: 227) en la que se reconoce una ciudadanía que necesita ser asistida en todo momento, una subjetividad singular sometida al continuo reconocimiento institucional cada vez más extensivo (Wieviorka, 2003). Víctimas de violencia de género, estafas, accidentes de tráfico, negligencias médicas, amianto, terrorismo, explotación sexual, ébola, mobbing, afectados/as, etc. todas han pasado por un suceso que ha fracturado su biografía y, en muchos casos, ha reconfigurado su identidad.

En consecuencia ¿qué diferencia a unas víctimas de otras más allá de su experiencia personal? y ¿qué las lleva a ser definidas como víctimas de...? Si afirmamos que lo que caracteriza a las víctimas es la intensidad de su sufrimiento nos abocamos a establecer una jerarquización de estas en base a criterios psicológico-forenses o neurológicos (Fossum et al., 1982). Esto lleva a obviar el origen de la violencia. Incluso cabría pensar que la diferencia entre las víctimas está en su grado de traumatización. Ante la experiencia personal el trauma surge como un tema recurrente sin ser el único. Mientras que el sufrimiento puede quedar relegado a un ámbito estrictamente íntimo y personal, la víctima (emergente o reconocida) ha de jugar en un terreno sometido a reglas y fórmulas que no dependen ni de ella ni de su vivencia de la intensidad ni del tipo de catástrofe, independientemente de que espere o no algún tipo de restitución por parte de la comunidad (resarcimiento moral, reconocimiento social, ayudas económicas o erigirse como autoridad sufriente).

Si optamos por considerar que lo relevante de las víctimas es su etiología, esto nos lleva a reducir a las víctimas a las posibilidades de reparación o compensación por el tipo de catástrofe sufrida al igual que los baremos de compensaciones de las compañías de seguros. Sería casi tentador considerar que todas las víctimas son iguales más allá de la catástrofe originaria (accidente, enfermedad, atentado...). Recurramos al concepto de catástrofe como acontecimiento que supone un punto de inflexión en la configuración del sujeto tal como se entiende en la teoría de las catástrofes (Thom, 1972; Zeedman, 1979) y no para describir la gravedad del suceso sufrido. Un punto en el que se produce una histéresis en la que ya no es posible reconstruir las mismas condiciones del sistema y, en este caso, en la que los agentes quedan redefinidos en un nuevo plano constituido por una víctima y un victimario (con todos los dispositivos expertos que se activan siendo el caso).

La singularidad de las víctimas no se sitúa ni en el origen ni en su grado de sufrimiento, sino en el proceso de reconstitución de su identidad con respecto a ese marco institucional y experto que las configura y define hoy en día (Gatti, 2011). O dicho de otra forma, la constitución de las víctimas pasa por un proceso de legitimación e institucionalización - pensemos si no en la Ley del estatuto de la víctima de delito(España, 2015) a través del cual su identidad es reconfigurada por diferentes expertos/ as y dispositivos institucionales. Este proceso de construcción y reconstrucción de la identidad es específicamente significativo en el caso de la violencia de género pues, como mostraremos, los aparatos institucionales a los que acuden para salir de la violencia establecen no solo un itinerario (Dodier y Bardot, 2009) del que es imposible zafarse y que las revictimiza, sino que definen identidades fuertes (Gatti, 2007). Identidades 
que se dibujan en función del momento en relación a la violencia de género -antes y después-y que estas mujeres, más que encarnar, deben simular.

A diferencia de la víctima de tráfico, terrorismo o franquismo, la mujer objeto de malos tratos se ha visto abocada a tener que enfrentarse a una imagen pública muy definida, marcada por la falta de agencia y una necesidad de ayuda externa, alguien que necesita ser salvada de sí misma, misión que solo se entiende posible a través de un apoyo comunitario bien de redes familiares, amistades o apoyo experto (en ese caso las redes asociativas de iguales están ausentes) (Larrauri, 2008; Casado-Neira, 2014). Ella solo tiene que dar el primer paso para que se active un proceso de tutela, que no podrá parar, ni cuestionar. La capacidad de agencia que se le atribuye se reduce a un único momento: denunciar para dejarse salvar. Esta es la imagen que se ha ido construyendo a través de los discursos institucionales, pero en un contexto en el que se siguen dando otras formas de desigualdad de género producidas, mayormente, en los terrenos simbólico y laboral. Así, bajo otras formas, la violencia sigue estando presente y se perpetúa más allá de la catástrofe originaria. Aunque las secuelas son algo común al campo de las víctimas, no se trata en este caso de efectos negativos que aparecen como consecuencia de la causa originaria sino de un contexto que acompaña a la mujer en su condición de tal.

\section{Apunte metodológico}

Desde el año 2012 dentro del proyecto Mundo(s) de víctimas se ha venido abordando la irrupción de las víctimas de diferentes causas (terrorismo, tráficos, franquismo...) en el espacio social. Consideramos que la víctima de violencia de género es la que más ha marcado el discurso sobre la víctima de carácter no político. La actividad llevada a cabo por grupos e iniciativas ligadas al movimiento feminista ha puesto sobre el tapete una realidad que había sido irrelevante hasta el momento. Esto ha dado lugar a la puesta en marcha de numerosas medidas de apoyo y sensibilización que han tenido un impacto positivo en la percepción de la violencia contra las mujeres y que ha llevado, a su vez, a una centralidad del aparato judicial en el fenómeno. En consecuencia, el trabajo de campo del grupo de investigación se ha orientado a la realización de una serie de entrevistas a mujeres objeto de malos tratos por parte de su pareja, a expertos/as y representantes del tejido asociativo, y documentado juicios por violencia de género.

El corpus total incluye, por un lado, entrevistas con 19 mujeres que han vivido una situación de malos tratos en diferentes momentos y con diversas trayectorias: con denuncia, sin denuncia, que han pasado a ser partes activas del tejido asociativo, recientes en su experiencia o no, con hijos/as o sin ellos/as, agredidas de forma reincidente, con juicios pendientes, etc. Y, por otro lado, 17 entrevistas con expertos/ as en violencia de género y atención a sus víctimas, así como representantes del tejido asociativo. En esta ocasión nos centraremos explícitamente en las referencias a los testimonios de las mujeres en situaciones de violencia, con la inclusión del testimonio de una experta (véase tabla 1 al final). 


\section{Los hitos de la víctima simulada}

La violencia de género ha saltado del ámbito de lo privado para situarse como parte de la discusión pública. Este proceso ha estado marcado por un alto grado de institucionalización en las respuestas, pudiéndose afirmar que se ha convertido en una cuestión de Estado. En el proceso de institucionalización es en dónde podemos identificar lo definitorio de la víctima como parte de la res püblica. Las mujeres que han sufrido violencia machista presentan una etiología que ha sido establecida por la Ley Integral:

Art. 1.1. La presente Ley tiene por objeto actuar contra la violencia que, como manifestación de la discriminación, la situación de desigualdad y las relaciones de poder de los hombres sobre las mujeres, se ejerce sobre estas por parte de quienes sean o hayan sido sus cónyuges o de quienes estén o hayan estado ligados a ellas por relaciones similares de afectividad, aun sin convivencia. 2. Por esta Ley se establecen medidas de protección integral cuya finalidad es prevenir, sancionar y erradicar esta violencia y prestar asistencia a sus víctimas. 3. La violencia de género a que se refiere la presente Ley comprende todo acto de violencia física y psicológica, incluidas las agresiones a la libertad sexual, las amenazas, las coacciones o la privación arbitraria de libertad. (España, 2004)

Esto ha conllevado, y así lo establece la Ley Integral, a que el sistema judicial juegue un papel determinante, pues en la práctica solo se reconoce como víctima a aquellas mujeres que han presentado una denuncia o en aquellos casos en los que la fiscalía actúa de oficio. Todo el sistema se orienta así a garantizar sus derechos sociales, laborales y económicos de forma tutelar. Este proceso de judicialización se pone de manifiesto de una forma más palpable al considerar que el acceso de las mujeres objeto de malos tratos a diferentes derechos está reservado a aquellas que han adquirido su estatus institucional a través de una sentencia judicial (o en el proceso previo a). Con excepción del derecho a la información, todos los demás demandan esa condición previa: a la asistencia social integral, a la asistencia jurídica gratuita, a derechos laborales y prestaciones de la Seguridad Social, a derechos de las funcionarias públicas y a derechos económicos.

Es más, las estadísticas de violencia de género ofrecen una imagen en la que la violencia de género se entiende como un fenómeno con una clara dimensión penal. Así en los datos oficiales sobre violencia del Instituto de la Mujer y para la Igualdad de Oportunidades (2015) se establecen cinco ámbitos: judicial (personas condenadas, enjuiciadas y denuncias), delitos contra la libertad sexual (abuso, acoso, agresión sexual, libertad e indemnidad sexual), macroencuesta sobre maltrato (mujeres autoclasificadas y consideradas técnicamente -sic- como maltratadas), prostitución y tráfico (víctimas de prostitución, tráfico y autores), y víctimas mortales por violencia de género; de los cinco únicamente la macroencuesta usa parcialmente un criterio no judicial a la hora de contabilizar los casos al preguntar por la autopercepción. En la misma línea el Observatorio de la Violencia de Género de la Fundación Mujeres (2015) en su apartado de documentos de indicadores remite al informe del Observatorio contra la Violencia Doméstica y de Género del Consejo General del Poder Judicial (2014). Esta incidencia 
en el enfoque penal también la podemos encontrar en los datos ofrecidos por el Instituto Nacional de Estadística (2015) que bajo la rúbrica Hombres y Mujeres en España ya considera un apartado específico llamado Delito y Violencia en el que se recogen los datos de personas condenadas y de víctima mortales por violencia de género. De todos los aspectos relacionados con la violencia de género recogidos en la Ley Integral la contabilización de los delitos, y situaciones asimiladas, son objeto de un seguimiento exhaustivo y sistemático del que carecen el resto de los fines estipulados en los principios rectores, que comprenden desde medidas de sensibilización y colaboración ciudadana, hasta garantía de derechos, sistemas de tutela, formación o coordinación de profesionales e instituciones. La víctima de violencia de género es establecida en términos judiciales.

Otro de los aspectos recurrentes en la percepción de las mujeres es su experiencia de victimización secundaria ligada a su contacto con el sistema judicial más que en ninguna otra instancia (sanitaria, socio-asistencial o policial) en dónde hay una ruptura entre lo que esperan de él (una salida a su situación) y lo qué encuentran (un proceso complejo, insatisfactorio y frustrante) (Cala y García Jiménez, 2014; Rodríguez y Bodelón, 2015), de mayor dimensión en el caso de las mujeres extranjeras que no hablan castellano (o lenguas oficiales) (Pérez Freire, 2015). Un itinerario a lo largo del cual se sienten continuamente cuestionadas y agredidas psicológicamente, en el que se han de convertir en víctimas para poder llegar a dejar de serlo.

Este itinerario se construye sobre dos lógicas identitarias autónomas: una, la de la agresión en la que se le atribuye ciertas características bien marcadas (pasividad, sumisión, falta de agencia...) que establece la identidad fuerte de víctima; otra, la de la reconstrucción, en la que hay una demanda de vuelta a un ideal de normalidad, otra identidad fuerte, en este caso, de mujer empoderada. Entre ambas se produce un estado liminal (Gennep, 2008) en el que se transita de una identidad a otra. Una situación, que prometiendo ser breve, termina prolongándose en el tiempo, dando paso a un estado de excepción en el que se acaba habitando.

A lo largo de su itinerario se producen tres hitos:

1. La revelación: en el momento de la denuncia que da paso a la intervención judicial y que supone su toma de conciencia como víctima de violencia de género.

2. La agencia: durante el itinerario institucional (especialmente judicial) que implica reconocerse en su pasado a través de una identidad victimal (caracterizada por la vulnerabilidad, pasividad, sumisión, etc.) pero que entra en conflicto con su propia experiencia de gestión de la situación de violencia.

3. La vida simulada: el mandato moral de abandonar inmediatamente esa identidad para transformarse en una mujer empoderada y de reconstrucción de una vida normal, que se acaba simulando. La vida normal como una anomalía dentro de la anomalía.

\subsection{La revelación}

A partir de las entrevistas con mujeres que han sufrido violencia de género se han detectado una serie de ideas recurrentes sobre cómo se produce la toma de conciencia de su situación. Su identidad se articula sobre la tensión entre la resistencia y la 
veracidad, la pasividad y la culpabilidad, en un juego de espejos frente a ellas mismas y la comunidad.

El descubrimiento de estar viviendo una situación vitalmente anómala -no se trata de la toma de conciencia, ni de la identificación como víctima- no se produce como consecuencia de campañas de sensibilización o información, sino a través de un hecho irrelevante y casi anecdótico. No en la propia situación del maltrato, ni en tiempo, ni en intensidad, ni es una señal, ya que estas no han faltado a lo largo del tiempo. El momento de la conciencia es activado por un gesto, un comentario determinado o una imagen que sitúa a la mujer como observadora de su propia situación, que la desplaza a un plano en el se que convierte en espectadora de sí misma. Aquí sería más correcto hablar propiamente dicho de revelación.

Desde la perspectiva de las mujeres la toma de conciencia de una situación de maltrato no se ve como su descubrimiento de víctima (en la que no todas coinciden), se trata del descubrimiento de su no-vida previa, de haber acabado en una existencia marcada por una anomalía afectiva, que convierte su vida en un trabajo continuo de desarrollo de estrategias de resistencia. $\mathrm{O}$, en otras palabras, de la asunción (no necesariamente aceptación) de un contexto de convivencia hasta que se produce la revelación:

En sí yo no pensaba que era violencia, pero vivía en violencia desde hace mucho, pero no físicamente sino psicológicamente. Y bueno, y en [fecha] ya una amenaza, y ya se acabó todo. (Entrevistada 1)

Yo también llevo trece años de relación con mi ex pareja, entonces lo que sucedía realmente tú lo ves incluso normal, porque estás en un estado tan difícil de entender, pero es así, que te parece normal. Yo estuve en mi caso trece años, todo lo que veía me parecía normal, pero luego ahora con la psicóloga y con todos, el asistente social y todo, me decían que no era normal, entonces tú es ahora cuando empiezas a ver que lo que tú estabas viviendo, eso no era normal. (Entrevistada 2)

Lo que no quiere decir que la mujer no conozca su situación, sino que no la asume como una situación de maltrato. La sombra de la sospecha no se despeja a través de un proceso de búsqueda consciente, se da de forma fortuita:

Es que salió así, o sea, no es que yo haya decidido nada, las cosas me han ido viniendo así, y poco a poco, a medida que han ido viniendo, me he dado cuenta... A ver, cuando se abre una lucecita al fondo de un caminito al principio la lucecita no te deja ver más que el puntito de la luz, la luz alumbra todo alrededor, y claro, ves la lucecita y luego empieza a dar la vuelta todo alrededor y janda coño!, y esa se junta con la otra, con la otra. Yo digo: "Yo tenía un virus ahí que me desmontó el ordenador, me lo desmontó del todo, y al virus me lo he ido comiendo y lo he ido matando y ahora, oye, los programas van". (Entrevistada 3)

Hay la latencia de una sospecha irreconocible pero que no adquiere forma hasta un momento en el que se produce una discontinuidad. Esto no tiene que ser otro episodio de agresión peor que otros anteriores, puede ser un comentario, un gesto de alguien más, pero que actúa de revulsivo; no es la gota que colma el vaso, es el momento en el 
que se desvelan los entresijos de la maquinaria de la convivencia de forma inmediata, es el momento en el que, abruptamente, se reconoce lo que se conocía. Ahora la mujer puede ver su vida desde bastidores.

Mi cuñada pegó un puñetazo en la mesa de la cocina y dijo: "[nombre de la entrevistada] saca agallas de donde sean. No puedes permitir más esta situación". Y el puñetazo que ella dio en la mesa a mí me minó. Pensé: ¡Qué poca cosa para ver lo que está pasando! Que mis hijos están en el medio, que yo como persona, lo buena que soy, que lo trato bien y no merezco este trato. ¡Qué poca cosa soy yo para no ser capaz de romper este círculo y salir de este círculo vicioso! ¡Qué poca cosa! Y entonces empecé, simplemente, a avergonzarme de mí. (Entrevistada 4)

Que se producen agresiones, ya lo sabe la propia mujer, pero que eso es una anomalía que tiene consecuencias de mucho más calado se descubre al ver bajo un nuevo prisma su papel en la vida de pareja. Ahora su comportamiento adquiere un nuevo sentido que destapa al victimario. Activado por un puñetazo en la mesa, no por la discusión familiar previa en la que estaban envueltos el agresor, su hermana y su cuñado, da pie a la posibilidad de generar una posición externa de espectadora bajo la que mirarse a sí misma. El hecho de que este cambio no se produzca ligado directamente a una agresión de mayor intensidad, sino que responde a un episodio más, pone de manifiesto cómo la toma de conciencia responde a un proceso con implicaciones sobre el sentimiento de culpabilidad que declaran muchas de las entrevistadas por no haber podido identificar las señales y por haber permanecido en la situación de maltrato.

\subsection{La agencia}

La capacidad de agencia es necesario abordarla en dos claves aparentemente contrapuestas: el empoderamiento (demanda externa) y la culpabilidad (valoración interna). Esta última nos ofrece la clave en la búsqueda de sentido a lo vivido. La cuestión de la culpabilidad es un punto en el que se produce un conflicto entre la corrección programática que niega que las mujeres sea corresponsables de la situación de maltrato y las declaraciones de mujeres maltratadas y expertas. El hecho de que haya una resistencia a hablar de la culpabilidad o la autoresponsabilización en la experticia más comprometida es explicable dado que las bases y el origen de la violencia de género no se sitúa en la coparticipación de la mujer. Asumir lo contrario supondría abonar el terreno para explicaciones que acaban cargando sobre la mujer la responsabilidad de la situación y no sobre el victimario. Sin embargo, no podemos obviar que el sentimiento de culpabilidad está ahí y forma parte del diagnóstico del problema porque:

La mujer que sufre violencia de género, en ese proceso de violencia y en ese proceso que decíamos que estaba unido a la educación, tiende a sentir culpabilidad por lo que ha pasado, una culpabilidad que se une al sentimiento del maltratador de que lo que está haciendo es porque ella tiene la culpa y además porque tampoco es tan grave como ella dice, porque es una "histérica". (Entrevista a experta) 
No se trata de una culpabilidad moral o legal, es una culpabilidad psicológica que larva las bases de su propia personalidad. La reversión del sentimiento de culpabilidad es uno de los elementos más críticos y que acompaña a las mujeres a lo largo de su itinerario, porque se ven como responsables de no haber identificado la situación de malos tratos, de no haber podido construir una relación satisfactoria y de no haber podido salvarlo a él. La carga de la culpabilización opera en tres ámbitos: hacia ellas, hacia él y hacia la vida en común; a lo que hay que sumar en muchos casos la que se da hacia los/las hijas - cuando se tienen- y hacia el resto de la familia: "[la] violencia de género no te lleva solamente a ti, sino que también conlleva a tus hijos, a tu familia, que se ve involucrada, todos acaban involucrados también" (Entrevistada 9). La explicación para no haber identificado a tiempo la situación se atribuye a una ceguera: "Es el padre de tus hijos, y la persona que conociste, con la que te casaste y tiene un valor para ti al margen del maltrato. Tú dices: "¡Jobá! A ver es el padre de mis hijos y yo a esta persona la quiero. Porque fue la persona..." Ahí se cumple cuando se dice que el amor es ciego" (Entrevistada 4).

Actitud justificada bien por el amor, bien por asumir el papel de madre y esposa, bien por entender la relación como una forma de redención en la que se sobreestima su capacidad de conseguir salvar al agresor de sí mismo. Lo que para muchas no es ninguna revelación, ya que conocen el tipo de comportamiento que él tiene:

yo antes pensaba que cuando estemos juntos, que cómo que yo le voy a salvar, yo lo voy a sacar de esto, que él es un buen chico, que tiene buen fondo. Entonces yo digo: "¡Madre mía qué estúpida he sido de creerme todo eso, de que yo tenía tantos poderes!" (Entrevistada 3)

También le vi maltratar y pegarle a su madre, y yo todo esto sacaba de que era que estaba enfermo, porque él sufre un trastorno obsesivo compulsivo, maníaco depresivo, y yo le achacaba todo a su enfermedad, y pensaba que le iba a cambiar, que le estaba ayudando, y yo quería ser buena. (Entrevistada 2)

Eres su madre, le cuidas, le vas a salvar. (Entrevistada 6)

La capacidad terapéutica que se atribuyen choca con la realidad de la relación en la que su autoestima basada, precisamente, en su capacidad de transformar el mundo a través del amor se ve no solo truncada, sino también se revuelve contra ellas atrapándolas en un tela de araña de chantajes emocionales, celos y control: "ahora pensándolo fríamente me siento víctima pero en parte culpable porque yo en cierto modo di pie a que él, a los celos, los celos de la pareja. ¡Cómo que me cegó pues!” (Entrevistada 10).

Una de las atribuciones inevitable en las víctimas de violencia de género es la ausencia de agencia. La demanda de empoderamiento, que es recurrente entre la experticia feminista, y sobre la que se articulan todos los discursos más críticos con las desigualdades de género, contrasta con la propia atribución de las mujeres, que se ven como autoengañadas, que han sufrido una distorsión de percepción de sus relaciones de pareja, pero no como sujeto pasivo.

Aquí se produce una fractura entre ambos tipos de narrativas (la experta y la vivencial), la mujeres se reprochan -sí- su incapacidad inicial de diagnóstico de la situación de violencia, aunque conscientes de ella, pero a la vez se reconocen como 
sujetos activos y empoderados en la gestión de su vida personal. Más que de la necesidad de empoderamiento cabría hablar de la de recuperación de su capacidad de acción tras asumir su fractura personal, o de cómo evitar que se disuelva la fuerza que les ha permitido gestionar las continuas crisis en el plano víctima-victimario. A nivel terapéutico se considera la recuperación de la autoestima como la llave para llegar a una situación de autonomía -o, en la práctica, de reconstrucción y redefinición del objeto del empoderamiento- que permite pasar de la focalización en el victimario y la relación en pareja a sí mismas. Se opera una puesta en valor de un sujeto recuperado para sí mismo, un paso de la vulnerabilidad al empoderamiento, de la pasividad a la agencia.

Esto se puede apreciar de forma muy clara cuando se describen agresiones en las que la mujer no se somete y abandona, lucha, resiste y considera alternativas, ante la falta de apoyo inmediato, como en este caso en el que la situación escala de forma fulminante:

Él se había hecho un bocadillo, lo dejó en el salón y los perros se lo comieron. En un momento me destrozó literalmente toda la casa, toda la casa me destrozó, hubo amenazas ya con cuchillos, con empujarme, con insultos, de todo, ahí es cuando realmente ya no pude más. Lo que realmente me fastidió, lo que realmente me da vergüenza ajena en la sociedad en la que vivo, es que no hubo un vecino que llamó a la policía, porque mira que yo gritaba. Gracias a que yo, no sé cómo hice, porque como él estaba tan drogado, le saqué el móvil y le mandé un whatsapp a mi madre, no sé cómo lo pude hacer, engañándole de mala manera, y vino la policía y la policía vio todo. (Entrevistada 7)

O como en este que se prolonga todo un periodo de más de diecisiete meses durante el que la mujer continúa la convivencia:

Se armó una asombrosa, ahí sí hubo físico, de todo. Pero, nada, aún estuvo todos los nueve meses de embarazo en casa tocando las narices evidentemente, nacieron los gemelos, y yo creo que tenían los gemelos ocho meses casi, que fue cuando a empujones le echamos de casa. (Entrevistada 8)

No se trata de formas de empoderamiento ejemplares en las que la mujer decida emanciparse absolutamente de la situación, pero ¿son posibles realmente esas formas de empoderamiento también en los casos posteriores en los que las mujeres cuentan con un apoyo experto? Atendiendo además a lo complejos, contradictorios y prolongados que son los procesos de reconstrucción de la persona después de una experiencia de malos tratos más bien cabe considerar que la narrativa del empoderamiento es un ideal que permite poner en marcha un procedimiento de identificación fuera de la violencia de género en el que la mujer se descubre como su centro de atención, dando paso a una nueva forma de agencia opuesta al sometimiento pasivo. Se pretende la invención de una nueva vida, de volver a vivir y sobre todo de perdonarse a sí misma.

Las mujeres víctimas afirman no ser pasivas durante el periodo de las agresiones, relatan múltiples estrategias para gestionar el contexto de violencia, entre otras cosas, 
contener al agresor, desarrollar su actividad laboral normal y mantener el rumbo. De hecho, los relatos parecen indicar que no hay una resignación frente a la violencia, sino que la sufren de manera activa: "Yo ni sumisa ni nada. Yo he sido víctima antes que de él, porque gracias a él he abierto los ojos, yo creo que era víctima de la sociedad y de mí misma, pero yo no me considero que haya sido sumisa" (Entrevistada 6), o "Yo tampoco, cuando podía, zurraba, cuando no podía, no" (Entrevistada 5). Afirman que son los dispositivos pensados para atenderlas y protegerlas los que las neutralizan y pasivizan. Tanto es así que aparece un rechazo frontal al concepto de víctima dado que semánticamente se vincula a pasividad, no agencia, y con ello se liga al modelo tradicional de feminidad. Ser víctima se descubre como una condición impuesta o inevitable para poder salir del ciclo de la violencia: acumulación de tensión, explosión, arrepentimiento (Walker, 1979).

Los relatos de las mujeres se articulan en dos lógicas diferentes, una centrada en la experiencia vivida con el agresor que se define por haber estado inmersas en una situación de violencia y aquella que está ligada a la puesta de la primera denuncia o a el proceso terapéutico en el que ya reconocen el imperativo de ser víctimas (aunque no se reconozcan como tales). Asumir el papel de víctima posibilita el tránsito por las diferentes instancias expertas que brinda apoyos pero también supone problemas y frustraciones. La condición de víctima genera unas posibilidades de reconocimiento en el espacio social que implican cubrirse con unos ropajes y asumir una mueca pensada para una puesta en escena orientada a un público que ya ha decidido el guión.

\subsection{La vida simulada}

La trayectoria de una mujer con una experiencia de malos tratos se puede entender como un salto entre estados en un sistema dinámico, donde se produce una alteración radical a través de una pequeña perturbación en las condiciones dadas (Thom, 1972). La mujer traspasa una discontinuidad que la sitúa en un nuevo plano en el que reconfigurar su existencia y su identidad: de un punto previo a una relación marcada por las agresiones a una búsqueda de salida a esta, con o sin ayuda. La salida de la situación de malos tratos supone un cambio de estado en el que se ha de reconocer como víctima, se sienta o no cómoda en esta acepción. La acepte o no su trayectoria vital, va a pasar a estar definida por esta etiqueta.

El mandato que se expresa de forma recurrente en las campañas de institucionales, el "Hay salida a la violencia de género" - de la campaña ministerial de 2012 que se sigue utilizando ocasionalmente (MSSSI, 2016) - contrasta con la imposibilidad, primero, de satisfacer el ideal de la mujer empoderada (en gran medida también por condicionantes de tipo económico o material que no dependen exclusivamente de su voluntad) y, segundo, con la demanda de rehacer su vida más allá de su condición de víctima.

Ser víctima se revela además como un estado sujeto a múltiples fuerzas que lo hacen irrealizable. Se entiende como un paso imprescindible para tomar conciencia de la situación (reconocerse como víctima) rompiendo con el victimario, pero inmediatamente se le exige redefinirse por oposición a lo que la caracteriza: la falta de agencia. El estado ideal de víctima es el momento en que se pone el pie en un trampolín para impulsarse en una nueva dirección (pero nunca hacia atrás). A su vez, 
se prescriben formas muy claras de cómo ser víctima, especialmente es los procesos judiciales, pero también en las instancias socio-asistenciales: para unas la víctima ha de ser veraz (jurídico y policial) y para otras ha de querer salir de la violencia (socioasistencial y terapéutico). El ser víctima deviene en un estado imposible de satisfacer, sometido a tensiones vivenciales, demandas institucionales y el mandato de salir de la violencia. La mujer se ve abocada a un juego continuo de simulaciones para dar respuesta a todas estas demandas externas y propias.

En la práctica se observa cómo ese proyecto de reconstrucción personal es infructuoso, es un proceso sin meta alcanzable, porque:

La recuperación es muy dura. A veces igual no llegas a recuperarte del todo, es imposible. Entonces, como es muy larga la recuperación, no puedes estar siempre con lo mismo. Tú sabes que estás mal, sabes por lo que estás mal. Centrarte en terapia y estar bien, se te va quitando un poco ese concepto. Yo ya sé por qué estoy así, ya está. Es que estás muchos años en recuperarte y no te recuperas del todo. (Entrevistada 8)

Normalmente tras la salida de la situación de violencia se habla de una vida marcada sobre la que se va construyendo una nueva existencia, que se siente siempre lastrada e incompleta, en la que las marcas van más allá de las de las agresiones físicas. ¿Qué se demanda de la víctima? Que sea víctima y que deje de ser víctima, que cumpla los atributos de la victimización que la llevan a que se muestre marcada por la catástrofe para dar testimonio de veracidad, poder ser identificada por la comunidad y poder moverse por el espacio institucional. Pero que una vez adquirida esa etiqueta, la abandone y emerja de sus cenizas, como si todo el periodo ligado a la situación de maltrato pudiera ser purificado, extirpado como un tumor maligno. Solo así puede demostrar su inocencia o demostrar que no era merecedora de lo vivido. Aunque persiste una sombra de corresponsabilidad que se sustenta sobre un déficit: "Yo creo que es más falta de autoestima porque yo cuando me casé, yo no creo que estaba enamorada del mío" (Entrevistada 11). Quien se instala en la condición de víctima estaría demostrando que tiene un defecto, una imperfección que daría respuesta a la pregunta del porqué: "En el sentido de que, una no lo has visto, lo has consentido, y después que tienes algo sucio, tienes una mancha" (Entrevistada 12), aunque la respuesta esté en el victimario y en las desigualdades de género.

La simulación no implica una mentira, supone la asunción de un papel que es ajeno y extraño a su propia experiencia y en el no acaba de reconocerse plenamente. La vida simulada comienza durante la situación de maltrato (de normalidad hacia el exterior), en el proceso de denuncia-juicio (como una víctima creíble, que es pasiva, sufriente y consistente en sus declaraciones, negando su agencia, aunque fuera reactiva), hacia familia, amistades, vecinos/as y compañeros/as (objeto de compasión o solidaridad, dependiendo de las posiciones morales de cada uno/a), ante los servicios de asistencia (mostrando que está en una situación de vulnerabilidad y merece la atención) y en el apoyo terapéutico (haciendo patente que quiere rehacer su vida). Pero en ocasiones también se simula una autonomía con respecto al victimario: "te da de muerte, el 
tiparrejo me busca solo por sus conveniencias, amor por mi parte ya no hay, tengo como un... reconozco que tengo como una dependencia a él" (Entrevistada 12).

Ser víctima es no tener una vida normal, y darse cuenta de ello. Esto no conduce inmediatamente al reconocimiento como víctimas, sino que este concepto se asume (aunque se rechaza en permanencia) al entrar en contacto con los dispositivos. El objetivo no es salvar a la mujer, sino salvarla de sí misma, asegurarse de que queda libre de toda imperfección, lo que prevalece a la largo de todo el itinerario. La mueca que se adopta no es la mueca de las máscaras del teatro que cubren el rostro original y que se puede sacar y poner, la mueca es la cara auténtica contorsionada con la sonrisa del éxito de la reparación que satisface los objetivos de la experticia y reconforta al entorno de la mujer, aunque haya ocasiones en las que siempre vuelve a salir a la superficie la experiencia vivida, como nos narra una hija de una mujer maltratada:

Ella nunca lo llegó a superar, de hecho ella hay veces que aún vive con ese día a día, con su pareja que tiene ahora, pues la verdad es que le tiene una paciencia increíble, porque mi madre en algún momento sin motivo ni razón pues coge y le echa de casa, y claro, él mucha paciencia tiene, pero se muestra el día a día, está presente, aunque ya hace tiempo que pasó. (Entrevistada 9)

La mujer está abocada a habitar un territorio marcado por una tensión irresoluble: el regreso a un momento previo al descubrimiento del agresor. Una vida que ya no es posible recuperar en esa forma porque las marcas son profundas, indelebles, cicatrices que no se pueden borrar.

De la mujer que ha sufrido violencia machista se espera que rehaga su vida, que se convierta en una mujer sin "ese pasado", que supere su trauma en el sentido literal, que pase por encima de él. En las entrevistas realizadas hemos observado muy al contrario una negación de la posibilidad de reconstruir una vida normal. Primero, una vida normal como mujer se entiende que es toda aquella libre de violencia de género. ¿Es esto posible? Una respuesta positiva implicaría reconocer que no hay violencia de género estructural y sistémica, y que todo se reduce a un problema de agresiones dentro o alrededor de la pareja. Segundo, ellas declaran de forma recurrente como están sumergidas en una no-vida permanente, en una vida simulada como estrategia de supervivencia y con la que poder reconstruir los lazos con la comunidad (y la familia).

\section{Reflexiones finales}

En la violencia de género la victimidad es un recurso necesario que ha de ser asumido y que opera en los cuatros espacios expertos (judicial, sanitario, socio-asistencial y policial). De esta manera la mujer entra en un juego de simulación de identidades forzadas como víctima. La demanda, que hacen muchos/as expertas que trabajan con las mujeres, de que se debe respetar sus tiempos, apunta a la complejidad vital que muchas han de afrontar, pero establece una meta clara en un futuro más o menos lejano: la normalidad, siempre con el objetivo de no instalarse en la victimización. En este sentido las posibilidades de agencia quedan constreñidas por las que ofrece en marco 
jurídico y los protocolos de cuatro campos expertos, y el empoderamiento solamente puede ser llevado a cabo de acuerdo a estos.

La cuestión victimal es en el fondo de orden identitario, de cómo performa en el espacio social y cómo se reconstruye subjetivamente. Se demanda de la mujer que salga de la situación de violencia, que reconozca su condición de maltratada para poder salir así de la situación en la que parece atrapada. Baste echar un vistazo a las campañas institucionales estatales contra la violencia de género para ver cómo hay un claro eje basado en la idea de que el primer paso para salir de la violencia es saber leer las señales y romper la barrera de silencio, reconocerse ante los demás como víctima: "Si tu chico te controla el móvil. Cuéntalo" (2014) "No guardes silencio, no te calles. No a la violencia contra las mujeres" (2006), "Si ocultas la verdad nadie sabrá que necesitas ayuda" (1998) (MSSSI, 2016). Hay un mandato moral explícito que tiene como objetivo sacar a las mujeres objeto de malos tratos de su situación, pero este mandato moral se basa, primero, en la premisa de que ellas carecen de agencia y son pasivas, segundo, asume esto como una característica definitoria y común en todos los casos. En esta asunción quedan atrapadas tanto las mujeres que no se ven identificadas bajo estas características, como las propias políticas e iniciativas socio-asistenciales y los procesos judiciales que establecen un patrón claro de la víctima creíble o la buena víctima: la que se deja rescatar por los dispositivos.

En los discursos sobre la violencia de género vemos cómo se considera que la mujer ha de ser salvada de sí misma o, expresado de una forma menos cínica, empoderada a través de una toma de conciencia de su situación. Se establece así un mandato moral de reconocerse como víctima para poder dejar de serlo. No se trata únicamente de una toma de conciencia, ha de asumir su papel de víctima para encajar en las expectativas de los dispositivos expertos (socio-asistenciales, sanitarios, policiales y judiciales): vulnerabilidad, traumas -físicos y/o psicológicos-, pasividad y veracidad testimonial. Son precisamente los mecanismos de generación de certeza y veracidad los que nos van a hablar no de la víctima como sujeto sufriente, sino de la víctima como proyección social.

La víctima ha de ser y no ser, ha de desempoderarse para empoderarse, ha de dejar de gestionar las agresiones para gestionar la resaca de las agresiones y ha de victimizarse para desvictimizarse. El tratamiento institucional y el imaginario de la condición de víctima la cosifica y la petrifica situándola en una agencia tutorizada. La asunción de que la víctima es un agente pasivo y desempoderado que necesita ayuda externa y experta para dejar de serlo es algo que también quedará cuestionado. En este sentido se reclama el uso del término "superviviente" para definirse sobre una capacidad de agencia que se ve usurpada, así lo hace la Red de Mujeres Supervivientes con la puesta en marcha de la iniciativa de testimonios positivos que se define como: "Un programa de voluntariado en el que formamos a mujeres que han sido maltratadas para potenciar el papel activo de la mujer Superviviente como Agente de Cambio Social" (Fundación Ana Bella, 2015).

Como ya ocurrió con el testigo superviviente de las dictaduras del Cono Sur (Peris, 2002: 405) y de los campos de concentración nazis, las víctimas son los muertos y los Muselmänner, quienes aceptan la lógica del campo de concentración y siguen sus 
pautas de forma consecuente, lo que los lleva a la extenuación: "se sabe que están aquí de paso y que dentro de unas semanas no quedará de ellos más que un puñado de cenizas en cualquier campo no lejano y, en un registro, un número de matrícula vencido" (Levi, 2002: 50). Son quienes han perdido su capacidad de acción y son arrastrados hacia su final, personas que solo son cuerpos en posición fetal. Quien no ha muerto porta el testimonio. Si en ese caso se lucha contra el olvido a través de la construcción de una memoria colectiva dirigida a una comunidad universal para que no se vuelva a repetir en el futuro, en el caso de la violencia de género se trata más de una reclamación de agencia orientada a redefinir el estatus de la mujer objeto de malos tratos dentro de la comunidad, a empoderarla frente a ésa y frente a nuevas formas de sometimiento.

Se produce un doble juego institucional hacia la lucha contra la violencia de género y la construcción de la "buena víctima". Quien, además, se ha de convertir en el modelo de feminidad empoderada como si fuese capaz de neutralizar las demás formas de desigualdad de género y violencia. La mujer que ha sufrido agresiones es un sujeto sometido a fuerzas divergentes, tanto internas como externas, entre las que su identidad se reconforma (no reconstruye) sobre la pérdida sin volver al estado previo -a la manera de los casos de Oliver Sacks (2011)-. Se genera una posibilidad de existencia sobre una anomalía, una vida después de la catástrofe, que a nivel de las narrativas de empoderamiento y de la intervención se concibe como un fénix que renaciendo del trauma encarna a la mujer que debe ser capaz de desenvolverse de forma ideal entre los avatares del sistema sexo-género.

En un juego paradójico y aparentemente contradictorio hay un imperativo para que se reconozcan como víctimas, a la vez que no se puede constituir en un estado, más bien en un limes que ha de ser cruzado hacia la reconstrucción de una identidad previa sin mácula. A la vez que el proceso de reconocerse como víctima lleva implícita una victimización secundaria y a tener que confrontarse continuamente con los momentos de las agresiones en su itinerario por los espacios expertos, las mujeres han de gestionar la tensión entre una salida hacia el futuro (presentado como esperanzador y positivo) y el pasado (recurrente). La víctima tiene que ser víctima para dejar de ser víctima.

La víctima para ser auténtica ha de satisfacer una serie de expectativas. El respeto por los tiempos de las mujeres, que manifiestan algunos/as expertas, es un reflejo más de esa demanda implícita de normalización vital, en otras palabras, de rehacer la vida. Más allá de la victimización secundaria, el propósito de salvar y recuperar a las mujeres lleva a una retrovictimización, en este caso ya no marcada por la frustración de perspectivas no cumplidas, sino por la puesta en escena de una vida recuperada simulada.

La víctima de violencia de género se construye bajo la premisa de la madriguera de Alicia (Carroll, 2005) que la trasladará a un mundo nuevo de sentido inabarcable, una realidad habitable pero llena de agujeros de sentido que lastra las relaciones con el exterior y consigo misma. Y, al igual que Alicia, quien no se decide qué puerta atravesar queda atrapada sin posibilidad de marcha a atrás. 
Tabla 1: $\quad$ Perfil de entrevistadas citadas

\begin{tabular}{|c|c|}
\hline Entrevistada & Perfil \\
\hline 1 & 30-40 años, sin empleo, con hijos, con denuncia (condena absolutoria) \\
\hline 2 & $\begin{array}{l}\text { 50-60 años, con empleo intermitente, con hijos independizados, } \\
\text { con denuncia, maltrato en dos parejas }\end{array}$ \\
\hline 3 & 20-30 años, con empleo, con hijos, con denuncia \\
\hline 4 & $\begin{array}{l}\text { 30-40 años, con empleo, con hijos, con denuncia } \\
\text { (muerte de la pareja antes del juicio) }\end{array}$ \\
\hline 5 & 20-30 años, con empleo, con hijos, con denuncia \\
\hline 6 & 40-50 años, con empleo, sin hijos, con denuncia \\
\hline 7 & 30-40 años, con empleo, sin hijos, con denuncia \\
\hline 8 & 40-50 años, sin empleo, con hijos, con denuncia \\
\hline 9 & 18-20 años, estudiante, sin hijos, hija de mujer con denuncia \\
\hline 10 & 30-40 años, con empleo, con hijos, con denuncia \\
\hline 11 & 50-60 años, sin empleo, con hijos, sin denuncia \\
\hline 12 & 30-40 años, con empleo, con hijos, con denuncia \\
\hline Experta & Responsable de políticas de violencia de género, Gobierno Vasco \\
\hline
\end{tabular}

Fuente: Elaboración propia.

\section{Bibliografía}

Bebengoechea Bartolomé, M. (coord.) (2007): Informe anual del Observatorio Estatal de Violencia sobre la Mujer, Madrid, Ministerio de Trabajo y Asuntos Sociales.

Butler, Judith (2006): Vida precaria: el poder del duelo y la violencia, Barcelona, Paidós.

Cala, María J. y M. García Jiménez (2014): "Las experiencias de mujeres que sufren violencia en la pareja y su tránsito por el sistema judicial: ¿qué esperan y qué encuentran?", Anales de la Cátedra Francisco Suárez, 48, pp. 81-105.

Carroll, L. (2005): Aventuras de Alicia en el país de las maravillas, Barcelona, Ediciones Akal.

Casado-Neira, D. (2014): "Las marcas en el cuerpo de la víctima: la veracidad encarnada en la violencia de género", Kamchatka, 4, pp. 359-380. doi:10.7203/KAM.4.4057

Debén Alfonso, M. (2006): O tratamento penal da violencia contra as mulleres, Santiago de Compostela, Xunta de Galicia.

Dodier, N. y J. Barbot (2009): "Itinéraires de réparation et formation d'un espace de victimes autour d'un drame médical", en Thomas Périlleux y John Cultiaux, eds., Destins politiques de la souffrance, Toulouse, pp. 99-117.

doi: 10.3917/eres.peril.2009.01.0099. 
España (2004): Ley orgánica 1/2004, de 28 de diciembre, de medidas de protección integral contra la violencia de género. Disponible en: https://www.boe.es/boe/dias/2004/12/29/pdfs/A42166-42197.pdf [Consulta: 23 de junio de 2015]

España (2015): Ley Orgánica 4/2015, de 25 de abril, del estatuto de la víctima de delito. Disponible en:

http://www.boe.es/diario_boe/txt.php?id=BOE-A-2015-4606 [Consulta: 23 de junio de 2015]

Fossum, A. et al. (1982): "Psychosocial and social consequences of torture. A pilot study", Tidsskrift for Den Norske Laegeforening, 102(11), pp. 613-616, 635.

Fundación Ana Bella (2015): Red de mujeres supervivientes. Disponible en web: http://www.fundacionanabella.org [Consulta: 23 de junio de 2015]

Gatti, G. (2007): Identidades débiles. Una propuesta teórica aplicada al estudio de la identidad en el País Vasco, Madrid, CIS.

Gatti, G. (2011): "De un continente al otro: el desaparecido transnacional, la cultura humanitaria y las víctimas totales en tiempos de guerra global", Política y Sociedad, 48(3), pp. 519-536.

doi:10.5209/rev POSO.2011.v48.n3.36419

Gatti, G. (2014): “Como la [víctima] española no hay”, Kamchatka, 4, pp. 275-292. doi:10.7203/KAM.4.4141

Gennep, A. van (2008): Los ritos de paso, Madrid, Alianza Editorial.

Instituto de la mujer y para la igualdad de oportunidades (2015): Mujeres en cifras. Violencia. Disponible en:

http://www.inmujer.gob.es/estadisticas/portada/home.htm [Consulta: 23 de junio de 2015].

Instituto Nacional de Estadística (2015): Mujeres y hombres en España. Disponible en: http://www.ine.es/

Larrauri Pijoan, E. (2008): "Cinco tópicos sobre las mujeres víctimas de violencia... y algunas respuestas del feminismo oficia ", en Patricia Laureano Copello, María Luisa Maqueda A. y A. M. Rubio Castro (coords.), Género, violencia y derecho, Valencia, Tirant lo Blanch-Alternativa, pp. 311-328.

Levi, P. (2002): Si esto es un hombre, Barcelona, Muchnik.

Lorente Acosta, M. (2001): Mi marido me pega lo normal, Barcelona, Editorial Crítica.

MSSSI [Ministerio de Sanidad, Servicios Sociales e Igualdad] (2016): Campaña contra la violencia de género. Disponible en:

http://www.msssi.gob.es/campannas/campanas15/haySalidaUnete.htm [Consulta:

31 de marzo de 2016].

Observatorio contra la Violencia Doméstica y de Género del Consejo General del Poder Judicial (2014): Datos de denuncias, procedimientos penales y civiles registrados, órdenes de protección solicitadas en los juzgados de violencia sobre la mujer (JVM9 y sentencias dictadas por los órganos jurisdiccionales en esta materia en el segundo trimestre del año 2014. Disponible en:

http://www.observatorioviolencia.org/upload images/File/DOC1413808072

Violencia\%20sobre\%201a\%20Mujer\%20-\%202T\%202014.pdf [Consulta: 23 de junio de 2015] 
Observatorio de la Violencia de Género de la Fundación Mujeres (2015): Recopilatorio de conocimiento sobre Violencia de género. Disponible en: http://observatorioviolencia.org [Consulta: 23 de junio de 2015]

Pérez Freire, S. (2015) "Los/las intérpretes vistos por los/las expertas y por las víctimas", en M. del Pozo Triviño et al. (eds.), Construir puentes de comunicación en el ámbito de la violencia de género, Granada, Comares, pp. 101-112.

Peris Blanes, J. (2002): "Los restos del sujeto: memoria y testimonio de los campos de concentración", Anclajes, 6, pp. 381-408.

Rodríguez Luna, R. y E. Bodelón González (2015): "Mujeres maltratadas en los juzgados: la etnografía como método para entender el derecho 'en acción'”, Revista de Antropología Social, 24, pp. 105-126. doi: http://dx.doi.org/10.5209/rev_RASO.2015.v24.50645

Sacks, O. (2011): An anthropologist on Mars: Seven paradoxical tales, Nueva York, Pan Macmillan.

Thom, R. (1972): Stabilité structurelle et morphogènese, París, Ediscience.

Walker, L. (1979): The Battered Woman, Nueva York, Harper \& Row Publishers.

Wieviorka, M. (2003): “L'émergence des victimes", Sphera Pública, 3, pp. 19-38.

Zeedman, E. C. (1979): "Catastrophe Theory, Selected Papers 1972-1977”, IEEE Transactions on Systems, Man, and Cybernetics, 9(9), pp. 609-610. doi: 10.1109/TSMC.1979.4310286 